\title{
RNA aptamer-mediated interference of HCV replication by targeting the CRE-5BSL3.2 domain
}

\author{
Soledad Marton, Cristina Romero-López and Alfredo Berzal-Herranz \\ Instituto de Parasitología y Biomedicina "López-Neyra", IPBLN-CSIC, \\ P.T. Ciencias de la Salud, Av. del Conocimiento s/n, Armilla, 18100 Granada, Spain.
}

Running title: Inhibition of HCV-CRE function by RNA aptamers

*Correspondence should be addressed to:

Alfredo Berzal-Herranz

Instituto de Parasitología y Biomedicina "López-Neyra", IPBLN-CSIC,

PT. Ciencias de la Salud, Av. del Conocimiento s/n, Armilla, 18100 Granada, Spain.

aberzalh@ipb.csic.es

Tel: $+34958181648 \quad$ Fax: +34958181632 


\section{SUMMARY}

The RNA genome of hepatitis C virus (HCV) contains multiple conserved structural RNA domains that play key roles in essential viral processes. A conserved structural component within the 3 ' end of the region coding for viral RNA-dependent RNA polymerase (NS5B) has been characterized as a functional cis-acting replication element (CRE). This paper reports the ability of two RNA aptamers, P-58 and P-78, to interfere with $\mathrm{HCV}$ replication by targeting the essential 5BSL3.2 domain within this CRE. Structure probing assays showed the binding of the aptamers to the CRE to result in a structural reorganization of the apical portion of the 5BSL3.2 stem-loop domain. This interfered with the binding of the NS5B protein to the CRE and induced a significant reduction in $\mathrm{HCV}$ replication $(\approx 50 \%)$ in an autonomous subgenomic HCV replication system. These results highlight the potential of this CRE as a target for the development of anti-HCV therapies, and underscore the potential of antiviral agents based on RNA aptamer molecules.

Key words: HCV genome, CRE, RNA structure-function, RNA Aptamers. 


\section{INTRODUCTION}

Hepatitis $\mathrm{C}$ virus $(\mathrm{HCV})$ is the major cause of liver cirrhosis and hepatocellular carcinoma worldwide (1). Current therapeutic strategies based on the combination of interferon and ribavirin have enjoyed only limited success; the identification of new targets and the design of alternative therapies are therefore major goals in HCV research. The targeting of conserved viral genome regions is of particular interest in the quest for such therapies.

The HCV genome is a 9600 nt-long, positive single-stranded RNA molecule that encodes a unique open reading frame flanked by conserved untranslatable regions (5' and 3'UTRs) (Fig.1) (2-5). The genomic RNA acts as messenger RNA during early infection to generate viral proteins required for viral replication and infection (reviewed in 6-8). The regulation of these events involves functional RNA domains located throughout the entire genome. The initiation of HCV translation is directed by an internal ribosome entry site (IRES), most of which is located in the 5'UTR (Fig.1) $(9,10)$. Viral RNA synthesis initiates at the 3'UTR and is strongly dependent on the presence of a cis-acting replication element (CRE) at the 3' end of the coding sequence. Identified as a region of conserved structure and sequence $(11,12)$, this CRE folds into a cruciform structure defined by three stem-loops with different functional identities: 5BSL3.1, 5BSL3.2 and 5BSL3.3 (Fig.1) (12). The essential 5BSL3.2 domain consists of two GC-rich helices connected by an eight-base bulge and a 12-base apical loop $(11,12)$. Disruptions in either the sequence or its folding lead to HCV genomes incompetent in terms of replication (13). The 5BSL3.2 domain interacts with both viral polymerase NS5B (14) and distant RNA domains of the viral genome (Fig.1). Indeed, a kissing complex is established between 5BSL3.2 and 3'SLII in the 3' UTR that is important for viral RNA synthesis (13). The internal loop of 
5BSL3.2 is also involved in the formation of apical loop-internal loop (ALIL) interactions with structural elements located upstream in the NS5B coding sequence (15) and in the conserved apical loop of domain IIId in the IRES (16). This suggest the importance of long range RNA-RNA interactions in the modulation of multiple steps within the viral cycle. Together, these properties make the CRE region, particularly domain 5BSL3.2, a potentially good target for novel antiviral compounds.

RNA aptamers - short oligonucleotides that specifically bind their ligands with high affinity - are good candidates for targeting viral RNAs (17-20). These molecules access their targets by recognizing their three-dimensional folding; they therefore have an advantage over other inhibitory RNAs such as antisense oligonucleotides, ribozymes and siRNAs, which face greater challenges in terms of target sequence accessibility. The specificity of aptamers is also greater since it is determined by both the primary sequence and tertiary structure of the target (21). Extensive work has been performed on the isolation of RNA aptamers that efficiently bind to essential structural domains in viral RNA genomes (22-28).

The present work examines the effect on HCV replication of two RNA aptamers selected against the genomic HCV-CRE region. These molecules target the essential apical loop of the 5BSL3.2 domain, promoting structural reorganization that interferes with the proper recruitment of the viral polymerase. This was found to inhibit viral RNA synthesis in a stable subgenomic replicon system. These findings show that the CRE region is a potential target for interference with HCV replication, and confirm the efficacy of RNA aptamers as antiviral tools. 


\section{MATERIALS AND METHODS}

DNA templates and RNA synthesis

HCV-CRE ${ }_{194}$ RNA was obtained by in vitro transcription of the Sall linearized plasmid construct pUC18-T7HCV9181-9371, as previously described (29). The 3'HCV9181 RNA used in in vitro NS5B binding assays was obtained as described elsewhere (16). P-58 and P-78 aptamer RNAs were synthesized by in vitro transcription of Salldigested pUC19-derived plasmids containing the respective aptamer coding sequence in-between the EcoRI and Sall restriction sites. In vitro transcription reactions and RNA purification were performed as previously described (30).

The plasmid pET-NS5B $\Delta 21$ used for the production of recombinant NS5B $\Delta 21$ protein was obtained as follows. NS5B $\Delta 21$ DNA was produced by RT-PCR of total RNA from Huh-7 cells harboring a HCV subgenomic replicon (Huh-7 NS3-3') $(31,32)$. A total of 500,000 cells were lyzed with Trizol reagent (Invitrogen, Carlsbad, California, USA) to extract the required RNA, as recommended by the manufacturer. $100 \mathrm{ng}$ of this total RNA was reverse transcribed using the High Capacity cDNA Reverse Transcription Kit (Applied Biosystems, Foster City, California, USA) and a fraction of the resulting cDNA used for amplification with primers HCV-7999/Nhel 5'CATATGGCTAGCTCGATGTCCTACACATGGACA-3' and asHCV-9308_Xhol 5'GTGGTGCTCGAGGCGGGGTCGGGCACGAGACAGG CT-3' (restriction sites are shown in italics). The DNA product was then cloned in the Nhel and Xhol sites of the pET-24a plasmid (Novagen, Darmstadt, Germany).

Aptamer selection (SELEX) 
Aptamers were selected as previously described (29). Briefly, a theoretical starting RNA population of $1 \times 10^{18}$ variants was obtained by the in vitro transcription of a synthetic DNA template containing a 30 nt-long random sequence region. Selection was achieved by challenging the binding of RNA variants to biotinylated $H C V-C R E_{194}$ viral RNA fragments fixed to a sepharose-streptavidin column. The elution and amplification of active molecules were carried out as described in the mentioned protocol, as was the selection procedure, which was repeated for nine rounds under the outlined experimental conditions.

\section{Binding assays}

Binding assays were performed by incubation of $20 \mathrm{fmol}$ of ${ }^{32} \mathrm{P}{ }^{5}$ end-labeled aptamer (P-58 or $\mathrm{P}-78)$ with increasing concentrations $(10 \mathrm{nM}$ to $1250 \mathrm{nM})$ of unlabeled $\mathrm{HCV}-\mathrm{CRE}_{194}$ in the presence of binding buffer (2 $\mathrm{mM} \mathrm{MgCl}, 50 \mathrm{mM}$ sodium cacodylate, $300 \mathrm{mM} \mathrm{KCl}$ ). RNA molecules were independently denatured for $3 \mathrm{~min}$ at $95^{\circ} \mathrm{C}$ in binding buffer and transferred to ice for $15 \mathrm{~min}$. Reactions were initiated by mixing both RNA molecules at $37^{\circ} \mathrm{C}$, and stopped on ice after $30 \mathrm{~min}$. The resulting complexes were resolved in $5 \%$ native polyacrylamide gels in TB buffer (100 mM Tris- $\mathrm{HCl} \mathrm{pH}$ 8.3, $86 \mathrm{mM}$ boric acid) at room temperature. Gels were dried, scanned using a Storm 820 Phosphorimager (GE Healthcare, Little Chalfont, Buckinghamshire, United Kingdom) and analyzed using Image Quant v.5.2 software (26). Dissociation constant $\left(K_{d}\right)$ values were calculated using Sigma Plot v.8.02 software and adjusted with the equation $y=\left(B_{\max } x\right) /\left(K_{d}+x\right)$ as previously described (33), where $y$ is the percentage of complexed aptamer, $B_{\max }$ is the 
amplitude of the reaction, and $x$ is the concentration of the substrate HCV-CRE 194 RNA.

\section{RNA-RNA interaction probing assays}

Probing assays of the aptamer:HCV-CRE ${ }_{194}$ complex with RNase $\mathrm{T} 1$ and lead acetate were essentially performed as previously described (26). Briefly, binding reactions involved the use of trace amounts of the ${ }^{32} \mathrm{P} 5^{\prime}$ end-labeled aptamer or $3^{\prime}$ end-labeled $\mathrm{HCV}-\mathrm{CRE}_{194}$ plus 10 pmol of the unlabeled partner $\left(\mathrm{HCV}-\mathrm{CRE}_{194}\right.$ for aptamer probing or the inhibitor RNA for the substrate assay). Aptamer RNA probing assays were performed in the presence of $0.01 \mathrm{U}$ of RNase T1 (Ambion, Austin, Texas, USA) or $15 \mathrm{mM} \mathrm{Pb}^{2+}$ acetate, and incubated for $2 \min$ or $4 \min$ at $4^{\circ} \mathrm{C}$ respectively in the presence of $2.8 \mu \mathrm{g}$ of tRNA. Analysis of the HCV-CRE ${ }_{194}$ RNA was performed under the same conditions but incubation was allowed to proceed for $10 \mathrm{~min}$ or $20 \mathrm{~min}$ at $4^{\circ} \mathrm{C}$ respectively in the presence of $2.8 \mu \mathrm{g}$ of tRNA. Digestion reactions were stopped by the addition of $100 \mathrm{mM}$ EDTA and subsequent phenol extraction. RNA products were resolved by high resolution $7 \mathrm{M}$ urea $6 \%$ polyacrylamide denaturing gel electrophoresis. Gels were dried, scanned and analyzed as above.

Aptamer competition with NS5B 21 binding to the HCV 3' genome end

Recombinant NS5B $\Delta 21$ protein was purified as previously described (34) from Escherichia coli BL21 transformed with the construct pET-NS5B $\Delta 21$. To generate 3'HCV9181:NS5B complexes, the ${ }^{32} \mathrm{P}$-labeled HCV 3' end RNA was denatured by 
heating $1 \mathrm{~min}$ at $95^{\circ} \mathrm{C}$ and then cooled for $15 \mathrm{~min}$ at $4^{\circ} \mathrm{C} .0 .013 \mathrm{pmol}$ of HCV RNA were then mixed with $5 \mathrm{nM}$ of recombinant NS5B $\Delta 21$ protein in binding buffer $(5 \mathrm{mM}$ HEPES $\mathrm{pH} 7.9,2 \mathrm{mM} \mathrm{MgCl} 2,25 \mathrm{mM} \mathrm{KCl}$ ). This interaction was subjected to competition with increasing concentrations of the selected aptamers (15 to $2500 \mathrm{nM}$ ) or the unrelated $\mathrm{RNA}_{80}(26)$. Binding reactions lasted for $30 \mathrm{~min}$ at $37^{\circ} \mathrm{C}$ before being transferred to ice for $5 \mathrm{~min}$. The mixtures were then diluted to $100 \mu \mathrm{l}$ in the same buffer and applied to pre-soaked $0.45 \mathrm{~nm}$ nitrocellulose membranes (GE Healthcare). These membranes were then washed twice with binding buffer, scanned using a Storm 820 Phosphorimager (GE Healthcare), and quantification performed as previously described (26). The $\mathrm{IC}_{50}$ values were calculated using Sigma Plot v.8.02

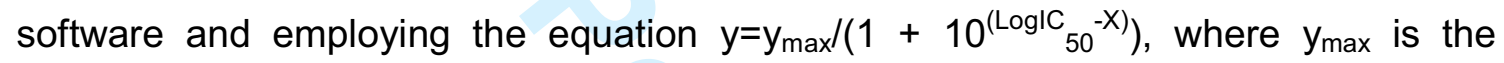
maximum percentage of relative binding of 3'HCV9181 RNA to the NS5B protein, $\mathrm{IC}_{50}$ the aptamer concentration that produces $50 \%$ of the maximum observed effect, and $\mathrm{X}$ the aptamer concentration.

Cell culture and transfection assays

Intracellular activity of the aptamer RNAs was evaluated in a human hepatocarcinoma cell line harboring an HCV subgenomic replicon system (Huh-7 NS3-3') (31,32), as previously reported $(27,35)$. Cell monolayers were maintained in Dulbecco's modified Eagle's medium (DMEM) supplemented with $10 \%$ heatinactivated fetal bovine serum (FBS) (Invitrogen) and $0.5 \mathrm{mg} \mathrm{ml}^{-1} \mathrm{G}-418$ at $37^{\circ} \mathrm{C}$ in a $5 \% \mathrm{CO}_{2}$ atmosphere. Twenty hours before transfection $\sim 80,000$ cells were seeded onto a 24 well plate in DMEM supplemented with 10\% FBS. Cells were transfected using TransFectin reagent (Bio-Rad, Berkeley, California, USA) with $3 \mu \mathrm{g}$ of the 
aptamer or the unrelated RNA molecule, $\mathrm{RNA}_{80}$, which was used as the internal standard of the assay. Cells were harvested $20 \mathrm{~h}$ post-transfection and used in subsequent analyses.

\section{Quantification of the HCV RNA replicon}

Intracellular HCV RNA was quantified as previously described (27). Briefly, total RNA was extracted with Trizol, following the manufacturer's instructions. $20 \mathrm{ng}$ of the extracted RNA were then used for reverse transcription with the High Capacity cDNA Reverse Transcription Kit (Applied Biosystems). A fraction of the cDNA was diluted with Taqman Gene Expression Master Mix (Applied Biosystems) and amplified by PCR over 40 cycles with specific oligonucleotides targeting the IRES region (C-149 and C-342) (36). The fluorogenic Taqman probe (FT-275) was added to the PCR mixture to a final concentration of $150 \mathrm{nM}$ (36). Quantification of the mRNA GAPDH was performed with the human GAPD (GAPDH) Endogenous Control kit (Applied Biosystems). Reactions were run in an ABI PRISM 7000 Sequence Detector System and the collected data analyzed using ABI PRISM 7000 SDS v.1.1 software (both from Applied Biosystems).

\section{RESULTS}

Isolation of aptamers targeting the CRE-5BSL3.2 domain

To identify RNA molecules that specifically bind and possibly interfere with the activity of the CRE located at the 3 ' end of the NS5B coding region (11), a SELEX procedure (37) was performed in which the target was a 194 nt-long RNA fragment 
(HCV-CRE $\left.{ }_{194}\right)$ of the HCV-1b Con1 genome (29). The target fragment spanned from nucleotide 9181 to 9371 and included the essential domains 5BSL3.1, 5BSL3.2 and 5BSL3.3 that make up the CRE element (Fig. 2). Selection was performed as previously described (29). Sequence analysis of selected molecules allowed the identification of RNA aptamers P-58 and P-78 that contained the sequence motif GGYUGUG complementary to the 5BSL3.2 apical loop (Fig. 2) (29), suggesting this viral genomic domain to be their theoretical target site. Given the functional importance of the 5BSL3.2 domain for viral replication, RNA aptamers P-58 and P-78 were characterized.

Binding assays involving P-58, P-78 and their target HCV-CRE ${ }_{194}$ RNA were undertaken to determine the specificity of the aptamers. For this, $20 \mathrm{fmol}$ of ${ }^{32} \mathrm{P}$ internally labeled aptamers were incubated with increasing concentrations of unlabeled $\mathrm{HCV}-\mathrm{CRE}_{194}$ under the experimental conditions described in Materials and Methods. The complexes formed in the binding assays were resolved in $5 \%$ polyacrylamide gels (recognized by their gel mobility shift). Both P-58 and P-78 bound to their target with $K_{d}$ values of $0.57 \pm 0.09$ and $0.47 \pm 0.12 \mu \mathrm{M}$ respectively (values are the mean of three independent experiments). No binding was observed for the starting pool PO (data not shown), confirming the proper functioning of the selection procedure.

Identification of the interacting sites between the aptamers and the HCV-CRE ${ }_{194} R N A$ RNA probing assays were performed to identify the residues involved in complex formation between the aptamers and $\mathrm{HCV}-\mathrm{CRE}_{194}$. The secondary structure of the aptamer molecules was analyzed as follows. ${ }^{32} \mathrm{P} 5$ ' end-labeled RNA aptamers were 
subjected to partial digestion with $\mathrm{RNase} \mathrm{T} 1 \mathrm{or}^{2+}$, which preferentially recognize nucleotides in single stranded RNA regions ( $G$ residues for RNase T1 degradation and any nucleotide for lead). The information obtained from the degradation patterns produced by T1 was then used for secondary structure prediction using Mfold software (38) (Fig. 2B). The results predicted the minimum free energy structure of both aptamers to be a $\mathrm{Y}$ shape (Fig. 2B), in which the sequence motif complementary to the 5BSL3.2 domain $\left(\mathrm{G}_{43} \mathrm{GCUGUG}_{49}\right.$ in P-58 and $\mathrm{G}_{40} \mathrm{GUUGUG}_{46}$ in P-78) is mainly located in an apical loop (Figs. 2 and 3). These residues had clearly become resistant to cleavage by RNase $\mathrm{T} 1$ and lead in the presence of a molar excess of the unlabeled $\mathrm{HCV}-\mathrm{CRE}_{194}$ molecule (Fig. 3), thus confirming their involvement in the interaction with the target HCV RNA.

Reciprocal probing assays were subsequently performed to identify the target regions in the substrate molecule. For this, ${ }^{32} \mathrm{P} 3$ ' end-labeled RNA was partially digested with $\mathrm{T} 1$ and $\mathrm{Pb}^{2+}$ as described above. In the absence of inhibitor RNAs, the degradation pattern of the $\mathrm{HCV}-\mathrm{CRE}_{194} \mathrm{RNA}$ resembled that previously described (12), with the proposed unpaired nucleotides in loops and single-stranded regions sensitive to cleavage (Figs. $2 \mathrm{~A}$ and 4 ). In the presence of either aptamer, significant and reproducible changes were seen in the degradation pattern of the apical region of the 5BSL3.2 RNA domain, extending from the internal to the apical loop. The presence of $\mathrm{P}-58$ rendered nucleotides $\mathrm{C}_{9282}$ to $\mathrm{G}_{9286}$ within the apical loop partially resistant to degradation, whereas the nucleotides of the upper portion of the stem, from $G_{9271}$ to $U_{9281}$, and from $U_{9291}$ to $U_{9296}$, showed greater susceptibility to RNase $\mathrm{T} 1$ and $\mathrm{Pb}^{2+}$ degradation (Fig. 4A). Similarly, the presence of P-78 led to the clear protection of nucleotides $\mathrm{C}_{9282}$ to $\mathrm{C}_{9288}$ within the apical loop to $\mathrm{Pb}^{2+}$ degradation, but with greater accessibility from $U_{9277}$ to $U_{9281}$ (Fig. 4B). This conformational 
rearrangement rendered nucleotides $\mathrm{G}_{9297}$ to $\mathrm{C}_{9300}$ within the 5BSL3.2 internal loop partially resistant to $\mathrm{Pb}^{2+}$-dependent hydrolysis in the presence of either RNA aptamer (Fig. 4).

Competition for RNA-dependent RNA polymerase binding at the HCV genome 3 ' end It has been reported that the 5BSL3.2 domain interacts with NS5B RNA-dependent RNA polymerase (14). This raised the question of whether the binding and/or the structural modification of the 5BSL3.2 domain induced by aptamers P-58 and P-78 might interfere with NS5B recruitment by the whole 3' end of the HCV genome. To examine this, in vitro binding assays were performed involving the recombinant protein NS5B $\triangle 21$ and an RNA fragment that included $425 \mathrm{nt}$ of the most 3' end of HCV genomic RNA (containing the CRE region plus the 3'UTR [3'HCV9181]) $(16,35)$. Increasing concentrations of the aptamers P-58 and P-78 were used as binding inhibitors, and their $\mathrm{IC}_{50}$ values determined (Fig. 5). The results showed the effective inhibition of the NS5B $\Delta 21$ protein binding to its target RNA by the aptamer molecules in a concentration-dependent manner, with $\mathrm{IC}_{50}$ values in the $\mathrm{nM}$ range $(185 \pm 46 \mathrm{nM}$ for P-58 and $321 \pm 89 \mathrm{nM}$ for P-78). No inhibition of binding was observed when the assay was performed in the presence of the unrelated 80 nt-long RNA control molecule $\left(\mathrm{RNA}_{80}\right.$; data not shown) used to normalize the binding inhibition data obtained for the RNA aptamers. These data suggest that the aptamers' interaction with the 5BSL3.2 domain, and the subsequent structural change induced, efficiently impedes the binding of the viral RNA polymerase to the 3' end of the HCV genome.

Effect of aptamers in HCV replication 
To assess the effect of the aptamers on HCV replication, Huh-7 cells supporting the autonomous replication of the subgenomic HCV 1b-Con1 derived replicon, were transfected with the P-58 and P-78 aptamers independently. Total RNA was extracted $20 \mathrm{~h}$ post-transfection and the (+) HCV RNA strand quantified using real time RT-PCR, as described in Materials and Methods. Transfection with the unrelated $\mathrm{RNA}_{80}$ was used as an internal control. Figure 6 records the significant reduction seen in the HCV RNA levels when P-58 and P-78 were present (close to $50 \%$ compared to the control). These results confirm the potential of aptamers targeting HCV-CRE to interfere with HCV replication.

\section{DISCUSSION}

The identification and characterization of functional RNA domains in viral genomes opens up the possibility of designing novel antiviral strategies aimed at interfering with their activity $(17,20)$. Conserved RNA sequences have been extensively tested as potential targets for inhibitory RNA molecules. In particular, SELEX procedures have been successfully used to isolate RNA aptamers capable of binding to viral structural RNA domains with essential functions, such as the trans-activation response (TAR) element of human immunodeficiency virus (HIV), the HCV-IRES, and the HCV 3'X tail, among others $(22-28,39)$. The present work characterizes the efficiency of two aptamer RNAs - P-58 and P-78 - isolated by a SELEX procedure against the CRE region of the HCV $1 \mathrm{~b}$ genome. Both molecules share a common sequence motif complementary to the apical loop of 5BSL3.2 in the HCV-CRE. RNA probing assays indicate that this common motif is involved in both aptamers' interaction with viral RNA (Fig. 3). Interestingly, MFold software analysis, plus the 
structural restrictions derived from RNA probing assays with RNase T1, predict both aptamer molecules to have a Y-shaped structure (Fig. 2C), a conformation described for RNA aptamers identified as efficient inhibitors of other viral genomic structural domains $(22,40)$. The present results indicate that the interaction of these aptamers and the HCV-CRE target RNA lead to a refolding of the apical portion of the 5BSL3.2 (Fig. 4), involving nucleotides in the internal and apical loops as well as the helical region between them. Thus, the overall structural rearrangement of the 5BSL3.2 domain may be directly related to the inhibitory effect of the aptamers on HCV replication (Fig. 6).

5BSL3.2 is known to bind to HCV NS5B (14) at the time that the apical loop is involved in an RNA-RNA interaction with the distantly located apical loop of the 3' SLII structural domain within the 3'UTR sequences of the genomic HCV-RNA (13) (Fig. 1). Via its internal loop, 5BSL3.2 is involved in two additional functional interactions, one with a domain located within the NS5B coding region centered on nucleotide 9110 (15), the other with domain IIId within the IRES region (16) (Fig. 1). This network of interactions plays an important role in various essential steps of the viral cycle, such as viral replication and translation, suggesting it may be a key element in the modulation of the switch between them. The interference with any of these interactions may challenge the viral cycle, therefore these RNA aptamers have a great potential as base for the development of anti-HCV agents.

It has been shown that viral NS5B RNA polymerase binding to the 5BSL3.2 domain can be interfered with by 5BSL3.2 RNA decoys, but not with similar decoys lacking three nucleotides in the internal loop (14). In addition to its binding to the 5BSL3.2 domain, the polymerase binds to the poly $(U)$ and to the SLII domain, as well as to the linker between SLII and SLI within the 3' X-tail region $(41,42)$. Very recently it has 
also been shown that targeting of the SLIII domain within the 3' $\mathrm{X}$-tail region with antisense peptide nucleic acids (PNAs) interferes with the binding of the NS5B protein to the 3' $\mathrm{X}$-tail, though there is no evidence of a direct SLIII RNA-NS5B polymerase interaction (43). An explanation for the incomplete inhibition (80\%) of polymerase binding to the CRE region in the presence of saturating concentrations of either P-58 and P-78, might be the interaction of the polymerase with any of the other identified binding sites in the 3' end of the HCV RNA genome (43). It is also likely that the structural change induced by the P-58 and P-78 in the internal loop of 5BSL3.2 is responsible for the partial interference in the binding of the polymerase to the 3 ' end.

RNA aptamers P-58 and P-78 efficiently interfered with HCV replication in Huh-7 cells (Fig. 6). It has been shown in this system that the apical loop of 5BSL3.2 interacts with a complementary sequence in the SLII loop of the 3' X-tail, forming a kissing complex essential for replication (13). Therefore, one cannot rule out the possibility that the inhibitory effect on HCV replication induced by the aptamers might also be due to the interference with this or some other long distance RNA-RNA interaction, as mentioned above (15) (Fig. 1). Neither can it be ruled out that aptamers might interfere with the proper formation of the efficient replication complex, as previously described (43). The authors of the latter work also report that the treatment of HCV subgenomic replicons with antisense PNAs targeting the SLI, SLII or SLIII within the 3'X-tail RNA leads to the inhibition of HCV replication in the same range as described in this work (between 40 to $50 \%$ ) (43). They also show that the PNA targeting SLIII inhibits the formation of a replication-efficient RNA-NS5B dimer complex, suggesting it to be the cause of replication inhibition.

The lack of efficient treatments against HCV infection necessitates new therapeutic strategies be sought, and interfering with functional genomic RNA elements is an 
interesting option. These domains retain a conserved sequence and structure that imposes considerable constraints on genome plasticity, reducing the risk of appearance of escape variants, and therefore making them potential targets (44). $\underline{\text { This fact would contrast with other anti-HCV strategies aimed to inactivate viral }}$ proteins, like the recently approved HCV-NS3 protease inhibitors which main limitation is the rapid appearance of resistant variants (45). The present work reports the inhibition of replication of subgenomic HCV replicons by two independent aptamers targeting the CRE domain. The combined used of both aptamers or in combination with other aptamers targeting different structural genomic RNA domains might result in a strong inhibition of the HCV cycle. Work to test this possibility is currently underway at our laboratory. In addition to their potential use as novel HCV inhibitors, these molecules could also be used to further identify novel RNA-RNA interactions involving the CRE and to study their role in the viral cycle.

\section{ACKNOWLEDGEMENTS}

Thanks are due to Vicente Augustin for excellent technical assistance. This work was funded by grants to Alfredo Berzal-Herranz from the Spanish Ministerio de Ciencia e Innovación (BFU2009-08137), the Consejería de Economía, Innovación y Ciencia of the Junta de Andalucia (CTS-5077) and the Spanish National Research Council (CSIC) (200420E632). Soledad Marton is a recipient of a MAEC-AECI fellowship from the Spanish Ministerio de Asuntos Exteriores y de Cooperación. Cristina Romero-López was funded by grants 200420E632 and BFU2009-08137. Work at our laboratory is partially supported by FEDER funds from the EU. 


\section{REFERENCES}

1 Hoofnagle JH. Hepatitis C: the clinical spectrum of disease. Hepatology 1997; 26:15S-20S.

2 Choo QL, Kuo G, Weiner AJ, Overby LR, Bradley DW, Houghton M. Isolation of a cDNA clone derived from a blood-borne non-A, non-B viral hepatitis genome. Science 1989; 244:359-362.

3 Kato N, Hijikata M, Ootsuyama $\mathrm{Y}$, et al. Molecular cloning of the human hepatitis $C$ virus genome from Japanese patients with non-A, non-B hepatitis. Proc Natl Acad Sci U S A 1990; 87:9524-9528.

4 Kolykhalov AA, Feinstone SM, Rice CM. Identification of a highly conserved sequence element at the $3^{\prime}$ terminus of hepatitis C virus genome RNA. J Virol 1996; 70:3363-3371.

5 Takamizawa A, Mori C, Fuke I, et al. Structure and organization of the hepatitis C virus genome isolated from human carriers. J Virol 1991; 65:1105-1113.

6 Moradpour D, Penin F, Rice CM. Replication of hepatitis C virus. Nat Rev Microbiol 2007; 5:453-463.

7 Suzuki T, Aizaki H, Murakami K, Shoji I, Wakita T. Molecular biology of hepatitis C virus. J Gastroenterol 2007; 42:411-423.

8 Suzuki T, Ishii K, Aizaki H, Wakita T. Hepatitis C viral life cycle. Adv Drug Deliv Rev 2007; 59:1200-1212. 
9 Reynolds JE, Kaminski A, Kettinen $\mathrm{HJ}$, et al. Unique features of internal initiation of hepatitis C virus RNA translation. EMBO J 1995; 14:6010-6020.

10 Wang C, Sarnow P, Siddiqui A. Translation of human hepatitis C virus RNA in cultured cells is mediated by an internal ribosome-binding mechanism. J Virol 1993; 67:3338-3344.

11 Lee $\mathrm{H}$, Shin $\mathrm{H}$, Wimmer E, Paul AV. cis-acting RNA signals in the NS5B Cterminal coding sequence of the hepatitis C virus genome. J Virol 2004; 78:1086510877.

12 You S, Stump DD, Branch AD, Rice CM. A cis-acting replication element in the sequence encoding the NS5B RNA-dependent RNA polymerase is required for hepatitis C virus RNA replication. J Virol 2004; 78:1352-1366.

13 Friebe P, Boudet J, Simorre JP, Bartenschlager R. Kissing-loop interaction in the $3^{\prime}$ end of the hepatitis C virus genome essential for RNA replication. J Virol 2005; 79:380-392.

14 Zhang J, Yamada $\mathrm{O}$, Sakamoto $\mathrm{T}$, et al. Inhibition of hepatitis $\mathrm{C}$ virus replication by pol III-directed overexpression of RNA decoys corresponding to stemloop structures in the NS5B coding region. Virology 2005; 342:276-285.

15 Diviney S, Tuplin A, Struthers $M$, et al. A hepatitis $C$ virus cis-acting replication element forms a long-range RNA-RNA interaction with upstream RNA sequences in NS5B. J Virol 2008; 82:9008-9022.

16 Romero-López C, Berzal-Herranz A. A long-range RNA-RNA interaction between the 5' and 3' ends of the HCV genome. RNA 2009; 15:1740-1752. 
17 Marton S, Reyes-Darias JA, Sánchez-Luque FJ, Romero-López C, BerzalHerranz A. In vitro and ex vivo selection procedures for identifying potentially therapeutic DNA and RNA molecules. Molecules 2010; 15:4610-4638.

18 Puerta-Fernández E, Romero-López C, Barroso-delJesus A, Berzal-Herranz A. Ribozymes: recent advances in the development of RNA tools. FEMS Microbiol Rev 2003; 27:75-97.

19 Romero-López C, Sánchez-Luque FJ, Berzal-Herranz A. Targets and tools: recent advances in the development of anti-HCV nucleic acids. Infect Disord Drug Targets 2006; 6:121-145.

20 Toulme JJ, Darfeuille F, Kolb G, Chabas S, Staedel C. Modulating viral gene expression by aptamers to RNA structures. Biol Cell 2003; 95:229-238.

21 Darfeuille F, Reigadas S, Hansen JB, Orum H, Di Primo C, Toulme JJ. Aptamers targeted to an RNA hairpin show improved specificity compared to that of complementary oligonucleotides. Biochemistry 2006; 45:12076-12082.

22 Duconge F, Toulme JJ. In vitro selection identifies key determinants for looploop interactions: RNA aptamers selective for the TAR RNA element of HIV-1. RNA 1999; 5:1605-1614.

23 Fukuda K, Toyokawa Y, Kikuchi K, et al. Isolation of RNA aptamers specific for the 3' X tail of HCV. Nucleic Acids Symp Ser (Oxf) 2008:205-206.

24 Kikuchi K, Umehara T, Fukuda K, Kuno A, Hasegawa T, Nishikawa S. A hepatitis C virus (HCV) internal ribosome entry site (IRES) domain III-IV-targeted aptamer inhibits translation by binding to an apical loop of domain IIId. Nucleic Acids Res 2005; 33:683-692. 
25 Kolb G, Reigadas S, Castanotto D, et al. Endogenous expression of an antiTAR aptamer reduces HIV-1 replication. RNA Biol 2006; 3:150-156.

26 Romero-López C, Díaz-González R, Berzal-Herranz A. Inhibition of hepatitis C virus internal ribosome entry site-mediated translation by an RNA targeting the conserved IIIf domain. Cell Mol Life Sci 2007; 64:2994-3006.

27 Romero-López C, Díaz-González R, Barroso-delJesus A, Berzal-Herranz A. Inhibition of hepatitis C virus replication and internal ribosome entry site-dependent translation by an RNA molecule. J Gen Virol 2009; 90:1659-1669.

28 Tallet-Lopez B, Aldaz-Carroll L, Chabas S, Dausse E, Staedel C, Toulme JJ. Antisense oligonucleotides targeted to the domain IIId of the hepatitis C virus IRES compete with $40 \mathrm{~S}$ ribosomal subunit binding and prevent in vitro translation. Nucleic Acids Res 2003; 31:734-742.

29 Marton S, Berzal-Herranz B, Garmendia E, Cueto FJ, Berzal-Herranz A. AntiHCV RNA Aptamers Targeting the Genomic cis-Acting Replication Element. Pharmaceuticals 2012; 5:49-60.

30 Barroso-delJesus A, Tabler M, Berzal-Herranz A. Comparative kinetic analysis of structural variants of the hairpin ribozyme reveals further potential to optimize its catalytic performance. Antisense Nucleic Acid Drug Dev 1999; 9:433-440.

31 Larrea E, Aldabe R, Molano E, et al. Altered expression and activation of signal transducers and activators of transcription (STATs) in hepatitis C virus infection: in vivo and in vitro studies. Gut 2006; 55:1188-1196. 
32 Lohmann V, Korner F, Koch J, Herian U, Theilmann L, Bartenschlager R. Replication of subgenomic hepatitis C virus RNAs in a hepatoma cell line. Science 1999; 285:110-113.

33 Puerta-Fernández E, Barroso-del Jesus A, Romero-López C, Tapia N, Martínez MA, Berzal-Herranz A. Inhibition of HIV-1 replication by RNA targeted against the LTR region. Aids 2005; 19:863-870.

34 Bellón-Echeverria I, López-Jiménez AJ, Clemente-Casares $\mathrm{P}$, Mas $\mathrm{A}$. Monitoring hepatitis C virus (HCV) RNA-dependent RNA polymerase oligomerization by a FRET-based in vitro system. Antiviral Res 2010; 87:57-66.

35 Romero-López C, Berzal-Herranz A. The functional RNA domain 5BSL3.2 within the NS5B coding sequence influences hepatitis C virus IRES-mediated translation. Cell Mol Life Sci 2012; 69:103-113.

36 Martell M, Gómez J, Esteban JI, et al. High-throughput real-time reverse transcription-PCR quantitation of hepatitis C virus RNA. J Clin Microbiol 1999; $37: 327-332$.

37 Tuerk C, Gold L. Systematic evolution of ligands by exponential enrichment: RNA ligands to bacteriophage T4 DNA polymerase. Science 1990; 249:505-510.

38 Zuker M. Mfold web server for nucleic acid folding and hybridization prediction. Nucleic Acids Res 2003; 31:3406-3415.

39 Romero-López C, Barroso-delJesus A, Puerta-Fernández E, Berzal-Herranz A. Interfering with hepatitis $C$ virus IRES activity using RNA molecules identified by a novel in vitro selection method. Biol Chem 2005; 386:183-190. 
40 Kikuchi K, Fukuda K, Umehara T, et al. In vitro selection of RNA aptamers that bind to domain II of HCV IRES. Nucleic Acids Res Supp/ 2002:267-268.

41 Kim M, Kim H, Cho SP, Min MK. Template requirements for de novo RNA synthesis by hepatitis $C$ virus nonstructural protein $5 B$ polymerase on the viral $X$ RNA. J Virol 2002; 76:6944-6956.

42 Oh JW, Sheu GT, Lai MM. Template requirement and initiation site selection by hepatitis C virus polymerase on a minimal viral RNA template. J Biol Chem 2000; 275:17710-17717.

43 Ahn DG, Shim SB, Moon JE, Kim JH, Kim SJ, Oh JW. Interference of hepatitis C virus replication in cell culture by antisense peptide nucleic acids targeting the $\mathrm{X}$ RNA. J Viral Hepat 2011; 18:e298-306.

44 Simmonds P, Tuplin A, Evans DJ. Detection of genome-scale ordered RNA structure (GORS) in genomes of positive-stranded RNA viruses: Implications for virus evolution and host persistence. RNA 2004; 10:1337-1351.

45 Halfon $\mathrm{P}$, Locarnini $\mathrm{S}$. Hepatitis $\mathrm{C}$ virus resistance to protease inhibitors. $J$ Hepatol 2011; 55:192-206. 


\section{FIGURE LEGENDS}

Figure 1. Diagram showing the secondary structure of the 5' and 3' ends of the HCV genome. The diagram shows the 5' UTR plus domains $\mathrm{V}$ and VI located in the core coding sequence, all at the 5 ' end of the genome. The main structural domains (I-VI) and subdomains (IIla-IIIf) are identified. The translation start codon is indicated by an arrow. The representation of the 3' end includes: the 3' UTR containing the hypervariable region (HV), the polyU/UC stretch and the 3' X-tail including the SLI, SLII and SLIII domains; in addition the stem-loop domain that contains the translation stop codon (indicated by an arrow), the CRE region that includes the 5BSL3.1, 5BSL3.2 and 5BSL3.3 domains, and the SL9110 stem-loop domain are also included in the 3 ' end representation. Long distance RNA-RNA interactions are shown by dashed lines. The genomic fragment HCV-CRE 194 used in this work is shaded in the diagram.

Figure 2. Secondary structure of HCV-CRE 194 and RNA aptamers. (A) Sequence and secondary structure of the HCV-CRE 194 target RNA fragment. The 5BSL3.1, 5BSL3.2 and 5BSL3.3 structural elements are indicated. Numbers refer to the nucleotide positions of the HCV $1 \mathrm{~b}$ Con1 isolate (32). The sequence region complementary to the selected aptamer consensus sequence is shaded. (B) Sequence and proposed minimum energy secondary structure of the P-58 and P-78 aptamers, as determined by Mfold software using the experimental constraints obtained in RNase T1 analysis. G nucleotides highly accessible to RNase T1 are indicated by solid arrow heads. Consensus-selected complementary nucleotides to the 5BSL3.2 apical loop are indicated in bold. Nucleotides involved in the interaction with the HCV-CRE 194 target RNA are indicated in italics. 
Figure 3: Structure probing assays of the RNA aptamers. Structure probing assays for P-58 (A) and P-78 (B) complexed with the HCV-CRE ${ }_{194}$. Trace amounts of ${ }^{32} \mathrm{P} 5$ ' end-labeled aptamers were partially digested with $\mathrm{RNase} \mathrm{T} 1 \mathrm{or}^{\mathrm{Pb}}{ }^{+2}$ in either the presence $(+)$ or absence $(-)$ of $\mathrm{HCV}-\mathrm{CRE}_{194}$ RNA. Cleavage products were resolved in $10 \%$ high resolution polyacrylamide denaturing gels. $\mathrm{T} 1 \mathrm{~L}=\mathrm{T} 1$ cleavage ladder; $\mathrm{OH}=$ alkaline ladder; $\mathrm{C}=$ the corresponding aptamer incubated in binding buffer. Nucleotides involved in the interaction are shown on the right of each gel. Size fragments are indicated on the left.

Figure 4: Structure probing assays of the HCV-CRE 194 RNA. Trace amounts of the ${ }^{32} \mathrm{P} 3$ ' end-labeled HCV-CRE 194 RNA were partially digested with RNase $\mathrm{T} 1$ or $\mathrm{Pb}^{+2}$ in the presence $(+)$ or absence $(-)$ of P-58 (A) or P-78 (B). Specific cleavage products were resolved in $6 \%$ high resolution polyacrylamide gels. The RNA region where changes in the degradation pattern were observed in the presence of the RNA aptamers is indicated by a bracket labeled with an asterisk at the right of the gel. Structural domains are highlighted at the right of the gel. Specific nucleotide positions are indicated on the left of the gel. $\mathrm{T} 1 \mathrm{~L}=\mathrm{T} 1$ cleavage ladder; $\mathrm{OH}=$ alkaline ladder; $\mathrm{C}$ $=$ the corresponding aptamer incubated in binding buffer.

Figure 5: NS5B $\triangle 21$ binding to the HCV-3' end fragment: aptamer competition assays. ${ }^{32} \mathrm{P}-3$ ' end-labeled HCV-3' was incubated in the presence of increasing concentrations of P-58 $(\square)$ or P-78 (•). An 80 nt-long unrelated transcript of the pBSSK plasmid $\left(\mathrm{RNA}_{80}\right)$ (6) was used as a control of the competition reaction. The data show the percentage of the HCV 3' end bound to the protein in the presence of 
the aptamers compared to those recorded in the presence of the experimental control $\left(R N A_{80}\right)$. Values are the mean $( \pm S D)$ of at least three independent assays.

Figure 6: Aptamer inhibition of HCV replication in Huh-7 cells expressing a HCV subgenomic replicon. Cells were transfected with $3 \mu \mathrm{g}$ of P-58 or P-78. At 20 h post-transfection, total RNA was isolated with Trizol reagent and RT-PCR was performed using specific primers plus the Taqman probe for HCV 5' UTR or GAPDH mRNA. The results were analyzed using ABI PRISM SDS v.1.1 software (Applied Biosystems). HCV RNA levels were normalized to those obtained for GAPDH mRNA and referred to the control assay in the presence of $3 \mu \mathrm{g}$ of the RNA ${ }_{80}$. Significant differences $(P<0.02)$ between the relative HCV RNA amounts in the presence of aptamers (P-78 or P-58) with respect to the control RNA were observed. Values are $\underline{\text { the mean of three independent experiments } \pm \text { standard deviation. }}$ 
Figure 1

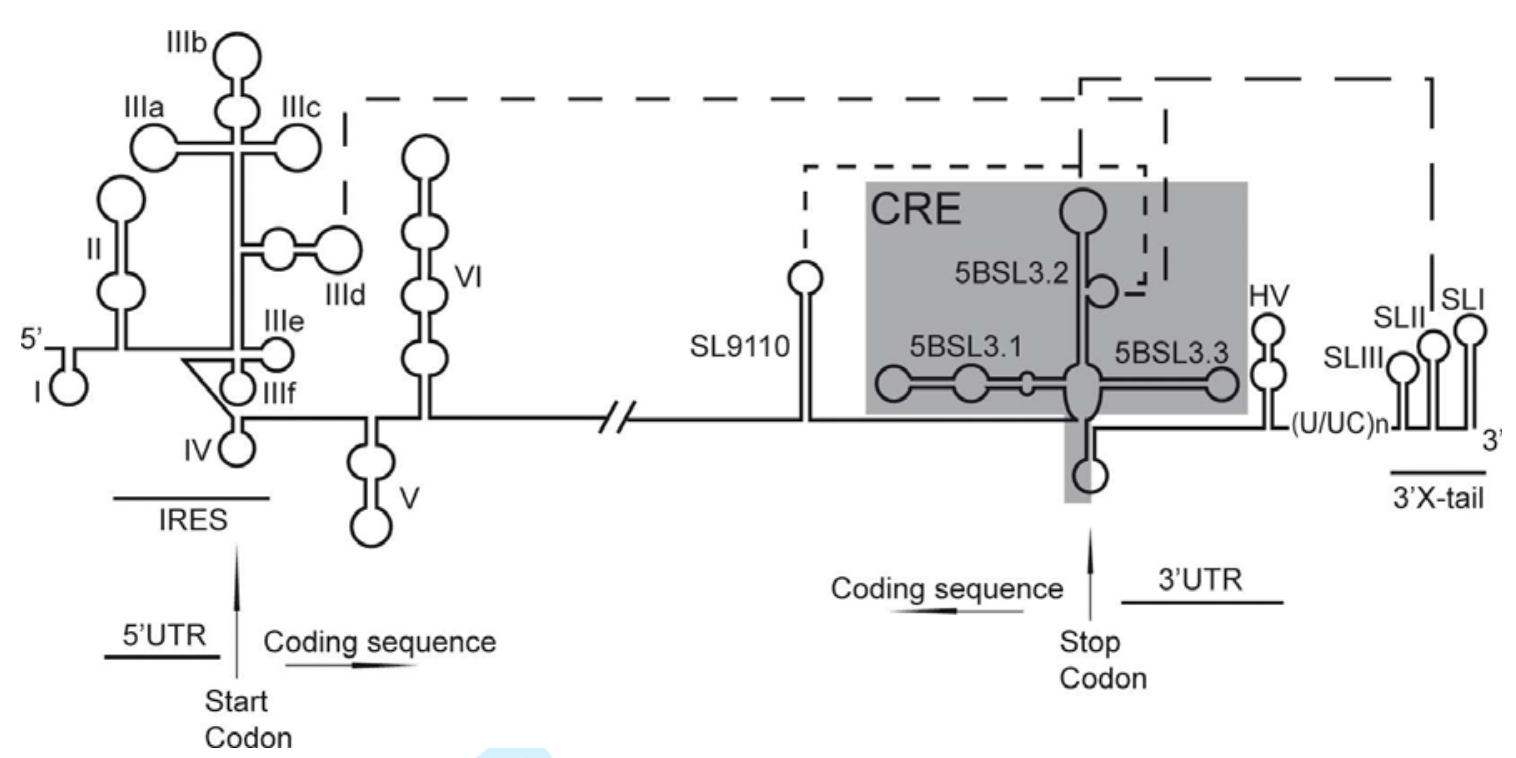




\section{Figure 2}

A

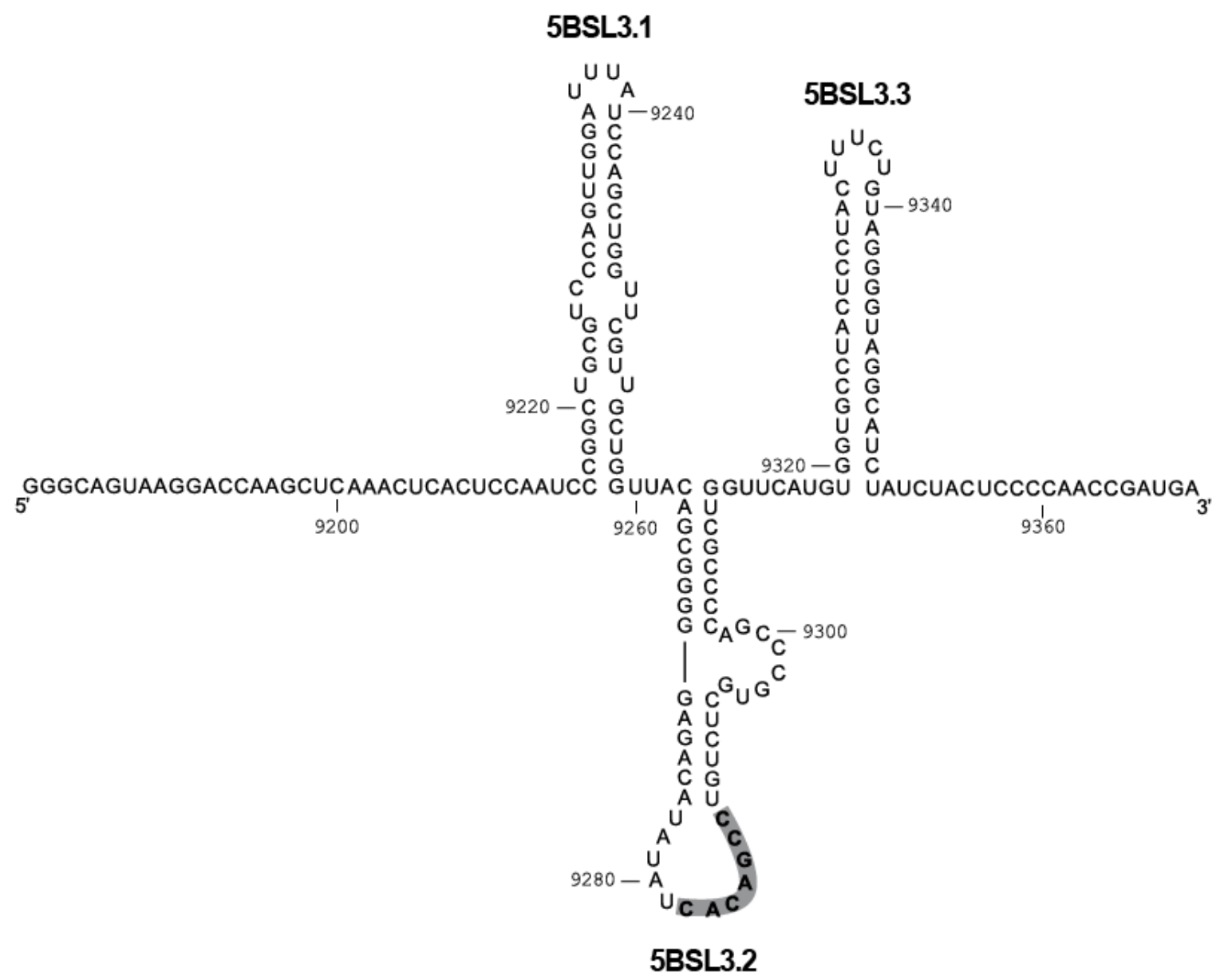

B
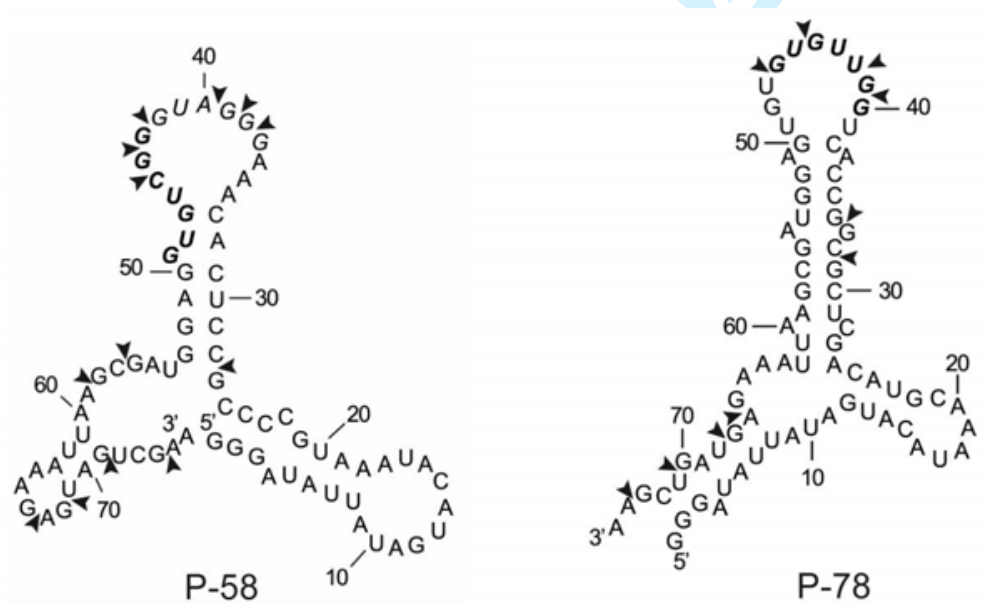


\section{Figure 3}

A

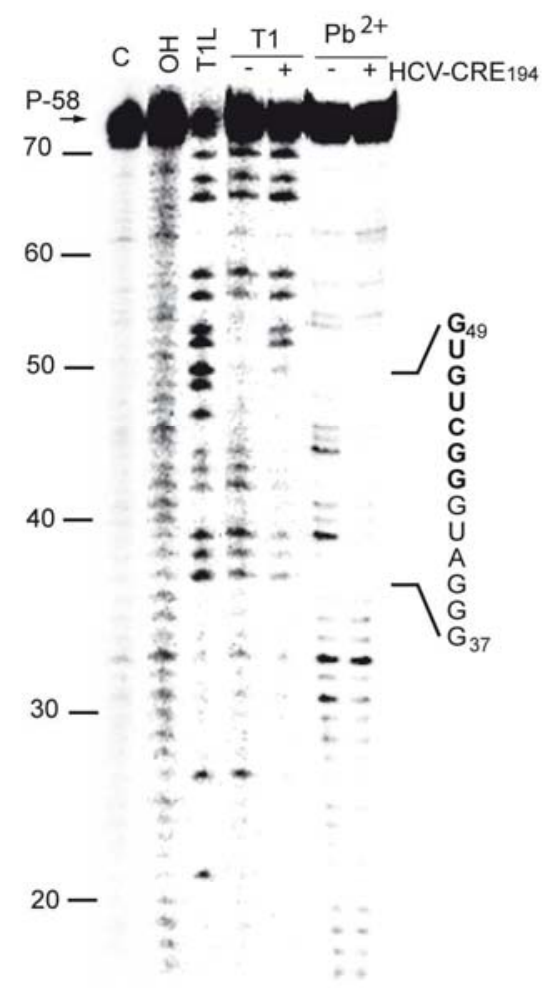

B

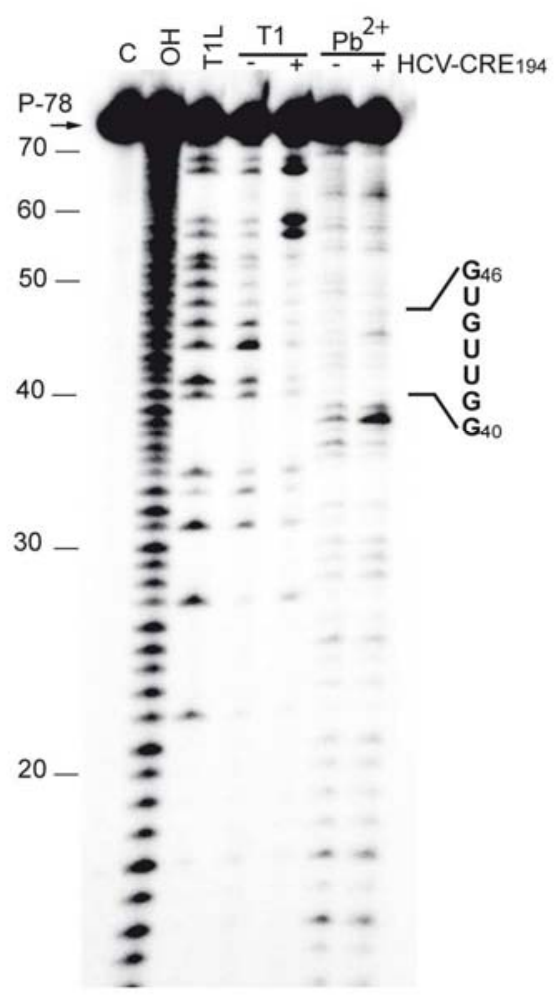


Figure 4

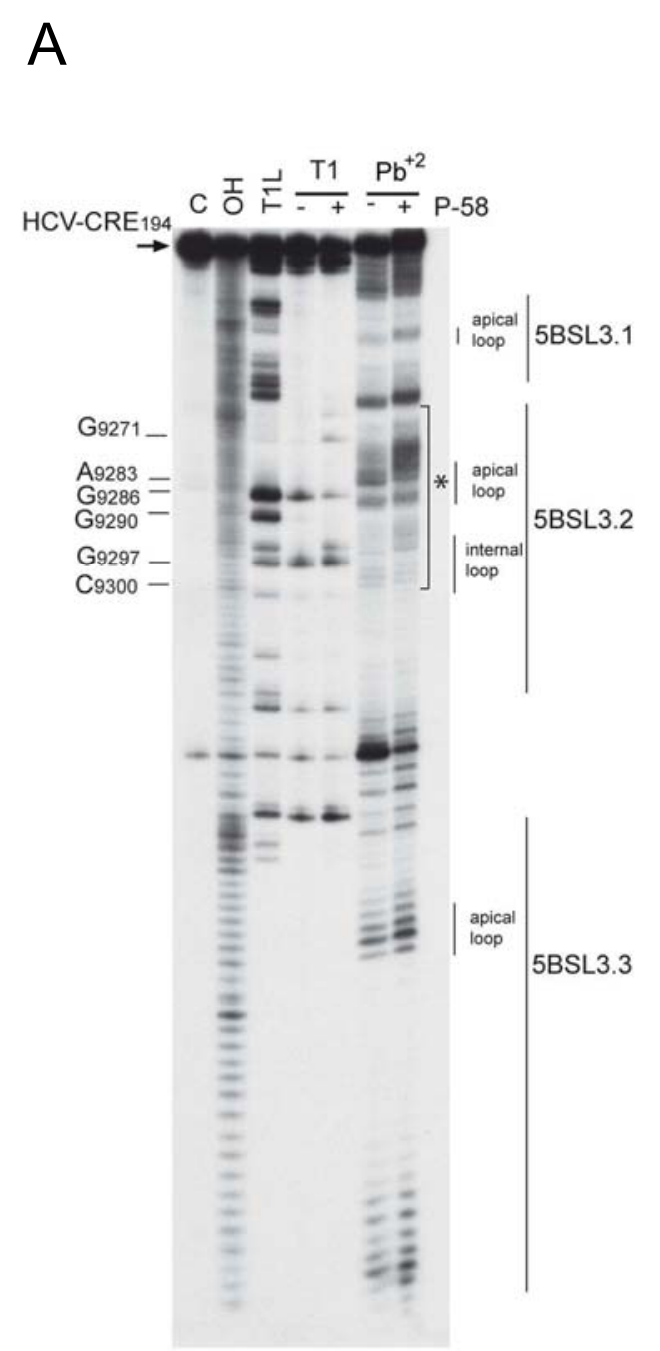

$\underline{\text { Revised }}$

\section{B}

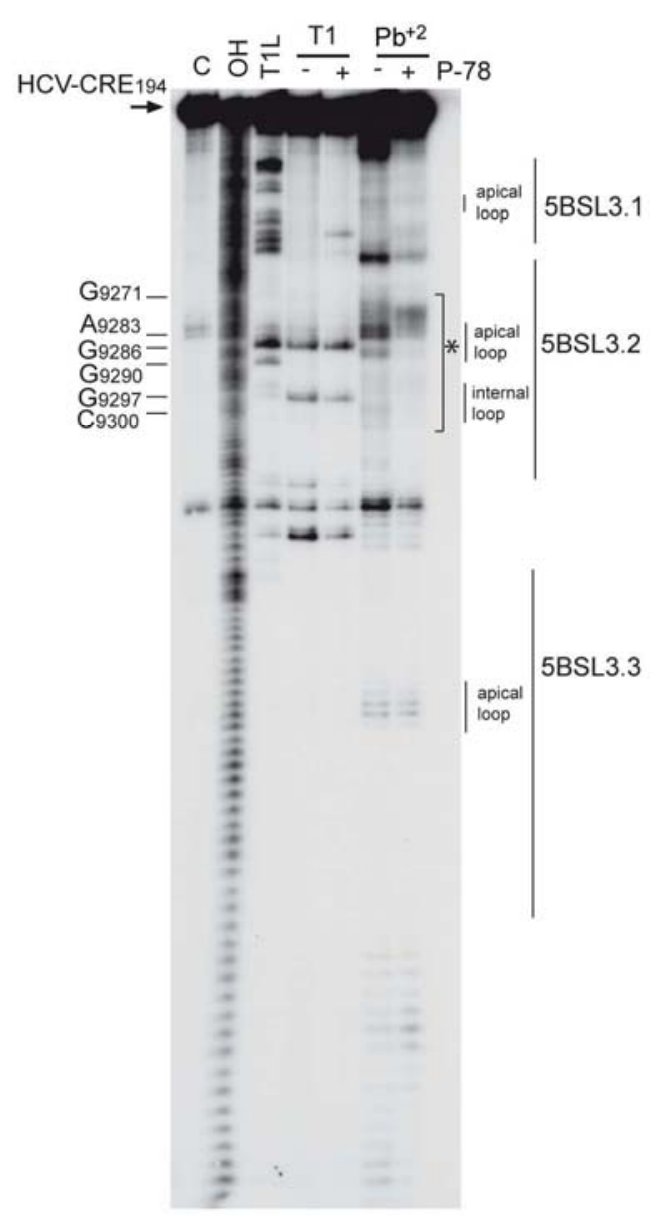


Figure 5

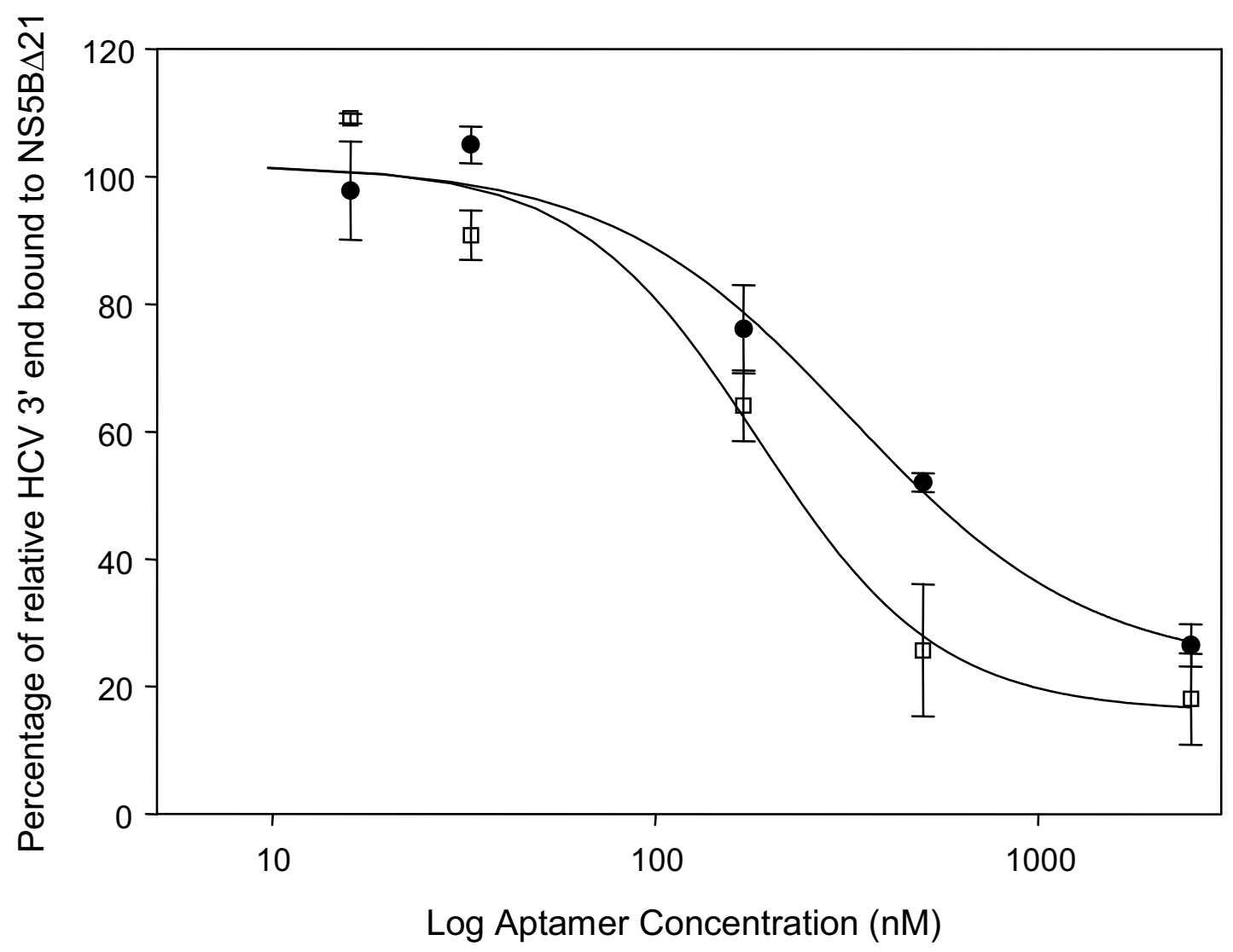


Figure 6

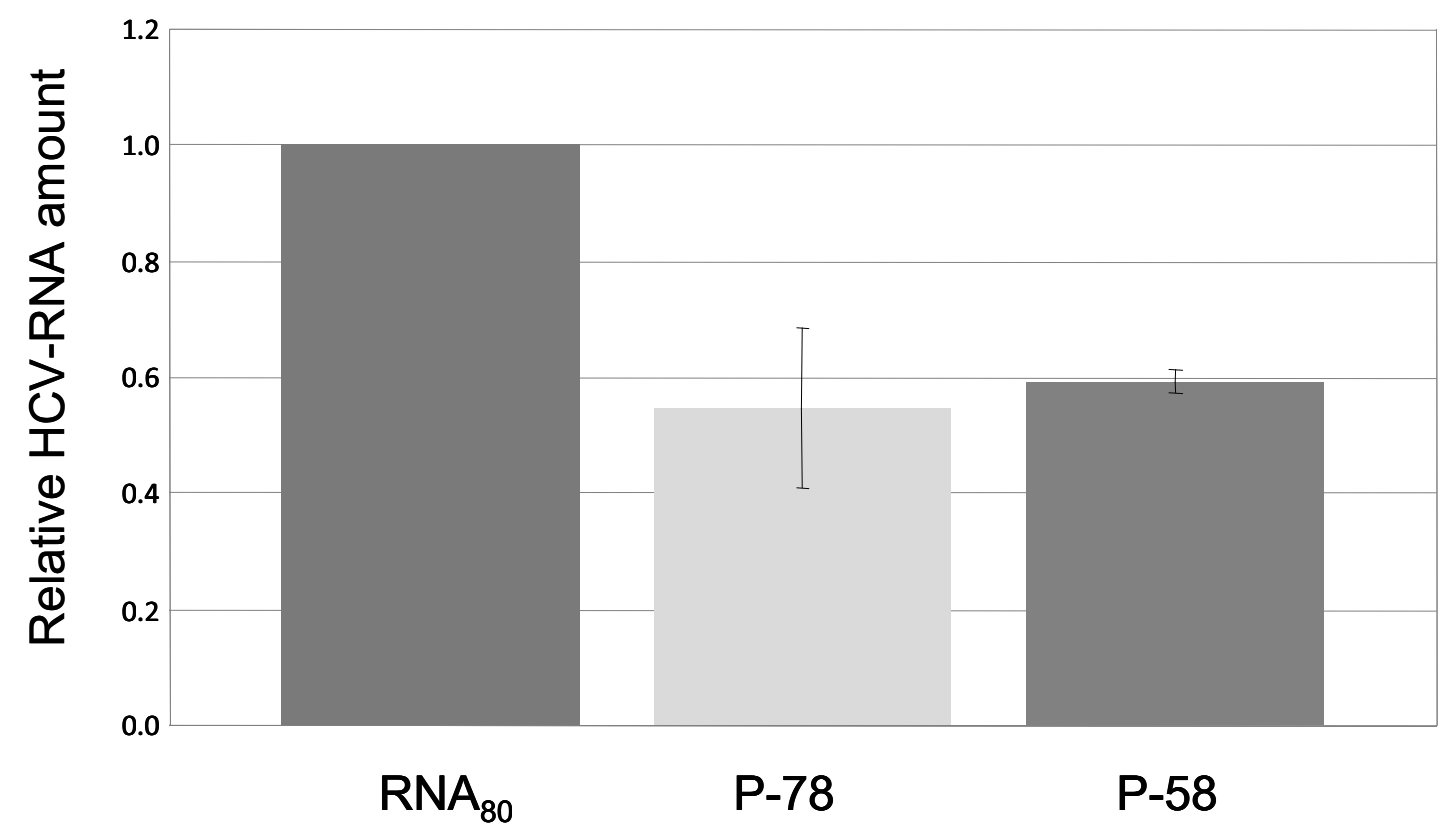

